\title{
Optimization of alkaline protease production by rational deletion of sporulation related genes in Bacillus licheniformis
}

\author{
Cuixia Zhou, Huiying Zhou, Huitu Zhang ${ }^{*}$ and Fuping Lu* (i)
}

\begin{abstract}
Background: Our laboratory has constructed a Bacillus licheniformis strain that secretes alkaline protease (AprE) with excellent enzymatic properties. B. licheniformis is generally regarded as safe and has a high industrial exoenzyme secretion capacity, but the host retains some undomesticated characteristic that increase its competitiveness and survival, such as spore-formation, which increases the requirements and difficulties in industrial operations (e.g. sterilization and enzyme activity control). Furthermore, the influence of sporulation on alkaline protease production in $B$. licheniformis has not been elucidated in detail.
\end{abstract}

Result: A series of asporogenic variants of the parent strain were constructed by individually knocking out the master regulator genes (spo0A, sigF and sigE) involved in sporulation. Most of the variants formed abortively disporic cells characterized by asymmetric septa at the poles and unable to survive incubation at $75^{\circ} \mathrm{C}$ for $10 \mathrm{~min}$. Two of them ( $\triangle$ sigF and $\triangle$ sigE) exhibited superior characteristics in protease production, especially improving the expression of the aprE gene. Under the currently used fermentation conditions, the vegetative production phase of $\triangle$ sigF can be prolonged to $72 \mathrm{~h}$, and the highest protease production of $\Delta$ sigF reached $29,494 \pm 1053 \mathrm{U} / \mathrm{mL}$, which was about $19.7 \%$ higher than that of the wild-type strain.

Conclusion: We first constructed three key sporulation-deficient strain to investigate the effect of sporulation on alkaline protease synthesis. The sigF mutant retained important industrial properties such as facilitating the sterilization process, a prolonged stable phase of enzyme production and slower decreasing trend, which will be superior in energy conservation, simpler operations and target product controlling effect. In summary, the work provides a useful industrial host with preferable characteristics and a novel strategy to enhance the production of protease.

Keywords: Sporulation, Asporogenic mutants, Alkaline protease, Bacillus licheniformis

\section{Introduction}

Alkaline protease is an industrially important hydrolytic enzyme that acts on the peptide bonds within the structure of proteins and is active even in the presence of organic solvents [1]. Consequently, it occupies the largest part of the global protease market share [2]. Since alkaline protease possesses excellent features of high catalytic power, specificity, water solubility, non-toxicity, edibility,

\footnotetext{
*Correspondence: hzhang@tust.edu.cn; Ifp@tust.edu.cn

Key Laboratory of Industrial Fermentation Microbiology, Ministry of Education, College of Biotechnology, Tianjin University of Science \& Technology, No. 29, 13th Road, Tianjin Economic-Technological Development Area, Tianjin 022 300457, People's Republic of China
}

environmental friendliness, etc. [3], it has been used in a wide-range of applications in the fields of detergents, leather processing, waste management, as well as the food and pharmaceutical industries [4].

In general, Bacillus species are efficient alkaline protease producers [5, 6], and especially Bacillus licheniformis is a promising industrial host strain for protein production, partly due to its 'Generally Recognized as Safe (GRAS)' status and its high enzyme secretion capacity $[7,8]$. B. licheniformis is widely distributed in soils where it helps recycle nutrients by producing and secreting macromolecule-degrading hydrolases such as amylases, proteases, cellulases and phosphatases [9]. In the 
challenging environment with a discontinuous supply of nutrients, abiotic stresses and competition from cohabiting microbes, Bacillus strains have developed a series of strategies to increase their competitiveness and survival, spore-formation being perhaps the best-known [10-12]. However, in industrial fermentation processes the microorganism is often confronted with similar adverse conditions (oxidative, osmotic stress, starvation for nutrients), and the bacteria can form spores to resist the hostile physical and chemical impacts in the bioreactor [13], which increases the requirements and difficulties of industrial operations such as incomplete sterilization, and reduced enzyme yield [14]. Most fermentation processes are susceptible to microbial contamination and require an energy-intensive sterilization process, which increases energy consumption and process complexity, contributing to the high costs of bio-products [15]. Sporulation is a "last resort" response to nutrient deprivation and stress [16] that includes developmental changes in cellular morphology, biochemistry and physiology. Due to its unique biological aspects, it has attracted interest from bacteriologists, developmental biologists and those interested in the practical aspects of spore formation [17].

The complex regulatory network of sporulation and the relationship between the involved factors have been largely elucidated in recent years [18]. On this basis, many efforts have been made in the development of industrial to improve the production of target proteins or inhibit the synthesis of toxic substances by escaping from detrimental sporulation. For example, deletion of spo0A in Clostridium tyrobutyricum led to high-level butanol production [19], while insertional inactivation of spoOA in the Clostridium botulinum type E strain resulted in significantly reduced production of botulinum neurotoxin [20]. Also, disruption of spoIIAC (sigF) for greater resistance to spore formation and increased secretion of $\beta$-cyclodextrin glycosyltransferase into the extracellular medium was reported in Bacillus subtilis [21], and one study found the greatest effect on the enhancement of enzyme productivity in the sigE-deleted mutant of $B$. subtilis [22]. While it had been reported that the production of alkaline protease is associated with the onset of sporulation in B. subtilis [23], the expression of eight genes encoding extracellular proteases was very poor or absent in the spo0A mutant [24]. Interestingly, almost all reports on the initiation of sporulation in the cases of $B$. subtilis found an association with such phenomena as protease production $[25,26]$. There are some interspecific differences in physiological and other metabolic mechanisms between $B$. subtilis and B. licheniformis, although the phylogenetic relationship of the two species is close [27]. However, few studies to date have systematically investigated the effects of sporulation on the production of alkaline protease in B. licheniformis. To our best knowledge, the sole exception is a single report on the production of extracellular enzymes in a spoIIAC mutant of B. licheniformis [28]. Accordingly, it is necessary and valuable to investigate the effect of sporulation on the production of alkaline protease and construct a highly productive chassis for industrial applications based on $B$. licheniformis cells without the undomesticated sporulation-related properties.

Consequently, we explored the production of alkaline protease in different sporulation-deficient strains of $B$. licheniformis. Here, we constructed three asporogenic mutants by disrupting spo0A, an initial responseregulator protein for entry into sporulation, and the two cell-specific sigma factors $\sigma^{\mathrm{F}}$ and $\sigma^{\mathrm{E}}$, which are activated shortly after asymmetric division and direct gene expression in the mother cell and forespore, respectively. The stability, viability, cell lysis, enzyme productivity and other relevant properties of the mutants were systematically investigated in order to inspect the effect of sporulation on cell growth and production of alkaline protease and to establish a stable food-grade $B$. licheniformis system as an industrial workhorse for the production of extracellular enzymes. Taken together, this work broadens our understanding of the relationship between sporulation and extracellular enzyme synthesis and provides a practical method to eliminate or avoid the undomesticated properties of Bacillus-based cell factories.

\section{Materials and methods}

\section{Bacterial strains and culture conditions}

All the strains used in this research are listed in Table 1. B. licheniformis 2709, BL $\Delta u p p$ was used as the original strain for genetic modifications, and the $E$. coli strains EC135 and EC135 pM.Bam were used for plasmid construction and methylation, respectively [29]. The shuttle expression plasmid pWH1520 was used to construct the gene knockout vectors.

LB medium was used as the basic medium for bacterial growth of Bacillus and E. coli, and the corresponding titers of antibiotics $(100 \mu \mathrm{g} / \mathrm{mL}$ ampicillin, $50 \mu \mathrm{g} /$ $\mathrm{mL}$ spectinomycin, $20 \mu \mathrm{g} / \mathrm{mL}$ tetracycline, $30 \mu \mathrm{g} / \mathrm{mL}$ 5 -fluorouracil) were added to the medium if necessary. The seed cultures ( $50 \mathrm{~mL} \mathrm{LB}$ medium) were cultivated in a $250 \mathrm{~mL}$ flask at $220 \mathrm{rpm}$ and $37{ }^{\circ} \mathrm{C}$ until the $\mathrm{OD}_{600}$ reached 1.2. The medium for production of alkaline protease was composed of $64 \mathrm{~g} / \mathrm{L}$ corn starch, $40 \mathrm{~g} / \mathrm{L}$ soybean meal5, $4 \mathrm{~g} / \mathrm{L} \mathrm{Na}_{2} \mathrm{HPO}_{4}, 0.3 \mathrm{~g} / \mathrm{L} \mathrm{KH}_{2} \mathrm{PO}_{4}, 0.7 \mathrm{~g} / \mathrm{L}$ thermostable amylase (Biotopped, Beijing, China), $\mathrm{pH}$ 7.2. The inoculum (2\%) was added into $100 \mathrm{~mL}$ of fermentation medium in a $500 \mathrm{~mL}$ flask, and was incubated at $220 \mathrm{rpm}$ 
Table 1 Strains and plasmids used in the study

\begin{tabular}{|c|c|c|}
\hline Strain or plasmid & Characteristics or purpose & Reference \\
\hline \multicolumn{3}{|l|}{ Strains } \\
\hline E. coli EC135 & Knockout vectors construction & Chinese Academy of Science \\
\hline E. coli EC135 pM.Bam & Plasmid DNA methylation modification & Chinese Academy of Science \\
\hline B. licheniformis $2709 \Delta u p p(B L \Delta u p p)$ & Parent host & This work \\
\hline B. licheniformis $\triangle \operatorname{sigF}(\mathrm{BL} \Delta \mathrm{F})$ & $\triangle$ sigF, sigF gene deletion & This work \\
\hline B. licheniformis $\triangle$ sigE (BL $\Delta \mathrm{E})$ & $\triangle$ sigE, sig E gene deletion & This work \\
\hline B. licheniformis $\triangle \mathrm{spo} 0 \mathrm{~A}(\mathrm{BL} \triangle 0 \mathrm{~A})$ & $\triangle$ spo0A, spo0A gene deletion & This work \\
\hline B. licheniformis CsigF (BL CF) & sigF gene complementation & This work \\
\hline B. licheniformis CsigE (BL CE) & sigE gene complementation & This work \\
\hline B. licheniformis CspoOA (BL COA) & spo0A gene complementation & This work \\
\hline \multicolumn{3}{|l|}{ Plasmids } \\
\hline pWH1520 & Shuttle expression vector, Amp ${ }^{r}$ (E. coli) and Tet' (Bacillus): MCS & Nankai University \\
\hline pWHU & pWH1520, upr T gene, cas9 gene & This work \\
\hline pWHF & Knockout vector, spo IIAC gene deletion & This work \\
\hline pWHE & Knockout vector, sig E gene deletion & This work \\
\hline pWHA & Knockout vector, spoOA gene deletion & This work \\
\hline pWHCF & Backcrossed vector, spo IIAC gene complementation & This work \\
\hline pWHCE & Backcrossed vector, sig E gene complementation & This work \\
\hline pWHCA & Backcrossed vector, spoOA gene complementation & This work \\
\hline
\end{tabular}

and $37{ }^{\circ} \mathrm{C}$ for the indicated time. All the fermentation experiments were performed at least three times.

\section{Gene knockout and genetic complementation in $B$. licheniformis $2709 \mathrm{BL} \Delta u p p$}

The genes spo0A, spoIIAC and sigE were deleted individually in $\mathrm{BL} \Delta u p p$ according to a previously reported method [7], as follows: First, the homologous arm (HA) was integrated into the vector: the left arm (L) and right arm (R) regions of spo0A were respectively amplified using primer pairs 0A-LF/0A-LR and 0A-RF/0A-RR (Additional file 1: Table S1), and fused by splicing overlap extension (SOE)-PCR using the primer pair 0A-LF/0ARR. The fused fragment was cloned into the pWHU vector at the SpeI restriction site. Subsequently, the synthesized sgRNA transcription cassette was integrated into the knockout vector, yielding pWHA, which was confirmed by diagnostic PCR and DNA sequencing (Fig. 1).

Then, the recombinant plasmid was transferred into $\mathrm{BL}$ $\Delta u p p$ by electrotransformation and tetracycline-resistant transformants were verified by colony PCR and plasmid extraction. The positive transformants were streaked onto $\mathrm{LB}$ plates and grown at $37^{\circ} \mathrm{C}$ for about $12 \mathrm{~h}$, after which diagnostic PCR (A-VF/A-VR) was used to verify the mutants, and DNA sequencing confirmed that the spoOA deficient strain (BL $\triangle A$ ) was constructed successfully. The spoIIAC and sigE deficient strains (BL $\Delta F$ and $\mathrm{BL} \Delta E$ ) were constructed in analogy to the construction of $\mathrm{BL} \Delta A$. The complemented strains were respectively constructed by introducing each of the specific backcrossed vectors including the complementary gene (Table 1) into the mutants using the same gene editing method. The main primers used for gene complementation were listed in the additional supporting file (Additional file 1: Table S2).

\section{Characterization of the mutants Morphological characteristics}

To determine the effects of sporulation on the cellular morphology of the bacteria, the morphological changes of different strains in the study were investigated via light microscopy (LM) (Nikon ECLIPSE Ci, made by Nikon corporation, Tokyo, Japan) to observe cell morphology by Crystal Violet stain and to visualize spores by Schaeffer-Fulton stain, and further confirmed in more detail via scanning electron microscopy (SEM). SEM was carried out based on reported method [30] with minor modifications as follows: Cells grown in LB medium or fermentation medium were collected by centrifugation $(5000 \times g$ for $5 \mathrm{~min}$ ) and washed in phosphate buffered saline (PBS) three times. Samples were fixed using $2.5 \%$ (v/v) glutaraldehyde in PBS overnight and washed three times with PBS to remove the remaining glutaraldehyde, then covered with platinum using a Q150R rotary-pumped sputter coater before observation using an SU8010 FE-SEM (Hitachi, Japan). 


$$
8
$$




\section{Viability of the strains}

In order to study the effect of sporulation on the strains' viability, the optical density at $600 \mathrm{~nm}\left(\mathrm{OD}_{600}\right)$, cell lysis and viable count were investigated. The growth curves of the strains were obtained using a microplate reader. First, an independent colony was transferred into a $250 \mathrm{~mL}$ flask with $50 \mathrm{~mL}$ of fresh LB medium and shaken at $37{ }^{\circ} \mathrm{C}$, then the $\mathrm{OD}_{600}$ of the bacterial suspension $(200$ $\mu \mathrm{L} /$ microwell) was detected using the Infinite 200PRO microplate reader (TECAN, Austria) every $2 \mathrm{~h}$. Cell lysis was inspected by observing cell morphology under the $\mathrm{LM}$, and counting the viable bacteria according to the method noted by the national standardization administration commission [31].

\section{Sporulation efficiency}

Sporulation efficiency of the strains in LB and fermentation medium after cultivation for different times was determined on an LB plate cultured for $12 \mathrm{~h}$ at $37^{\circ} \mathrm{C}$, as colony-forming units (cfu) per $\mathrm{mL}$ (spores) after heat treatment by incubation at $75{ }^{\circ} \mathrm{C}$ for $10 \mathrm{~min}$, compared with cfu per ml (viable count) of the unheated treatment sample.

\section{Alkaline protease synthesis in different mutants}

The alkaline protease productivity of the mutants and parent strain were studied using sampling at different incubation times in shake-flask fermentations. We investigated the alkaline protease activity in culture supernatants using the method according to the national standardization administration commission [32], observed the morphological changes by microscope and accurately counted the live bacteria of different samples; then alkaline protease activity per unit biomass were obtained. To evaluate the utility of the best engineered strain as a host for extracellular protein expression, the ability of the mutant possessing better alkaline protease production properties in shake flasks was compared with that of the parent strain in a 5 - L fermenter.

\section{Analysis of transcription levels}

The strains used in the study were cultured in liquid fermentation medium for $60 \mathrm{~h}$ at $37^{\circ} \mathrm{C}$ and the cells were collected at different cultivation times corresponding to the exponential phase and stable phase of alkaline protease activity per unit biomass. Total RNA was extracted using TRIzol ${ }^{\circledR}$ Reagent (Promega, USA) and the quality of the RNA was determined by agarose gel electrophoresis and the NanoDrop 1000 spectrophotometer (Thermo Scientific, USA). Trace DNA was digested using RNasefree DNase I (TaKaRa, Japan), and the first strand of cDNA was amplified using RevertAid First Strand cDNA
Synthesis Kit (Thermo, USA). To investigated the expression levels of alkaline protease genes, quantitative realtime PCR (qRT-PCR) were performed in an ABI Stepone Real-Time PCR System (Stepone plus, Thermo Scientific, USA). The primers in Additional file 1: Table S1 were used for amplifying the alkaline protease gene (AP-F/ AP-R) from the BL $\Delta u p p$ strain and the three other mutants, and $16 \mathrm{~S}$ rRNA (S-F/S-R) served as the reference gene to normalize the data. The transcriptional levels of the alkaline protease gene in the mutants at different culture times were compared with those of the control strain BL $\Delta u p p$ after normalization to the reference gene $16 \mathrm{~S}$ rRNA using the $2^{-\Delta \Delta \mathrm{Ct}}$ method. All the experiments were repeated three times.

\section{Batch fermentation}

Fed-batch fermentations were carried out with various strains in a 5-L bioreactor (MC-GS, Shanghai Bai Lun biological technology Co., Shanghai, China) with a 3-L working volume according to the optimum conditions of batch fermentation. The relevant fermentation media used in the study encompassed buttermilk plates comprising $4 \mathrm{~g} / \mathrm{L}$ casein in LB; liquid LB medium as the firstdegree seed medium; and second-degree seed medium comprising corn starch $50 \mathrm{~g} / \mathrm{L}$, soybean meal $30 \mathrm{~g} / \mathrm{L}$, $\mathrm{Na}_{2} \mathrm{HPO}_{4} 4 \mathrm{~g} / \mathrm{L}, \mathrm{KH}_{2} \mathrm{PO}_{4} 0.3 \mathrm{~g} / \mathrm{L}, 0.5 \mathrm{~g} / \mathrm{L}$ thermostable amylase, $\mathrm{pH}$ 7.3. The strain was first incubated in firstdegree seed medium $(50 \mathrm{~mL} / 250 \mathrm{~mL})$ at $37{ }^{\circ} \mathrm{C}$ for $8 \mathrm{~h}$, then the bacterial suspension was streaked onto buttermilk plates and cultured at $37^{\circ} \mathrm{C}$ for $36 \mathrm{~h}$. The colony with relevant bigger transparent zone around it was picked into the first-degree seed medium $(50 \mathrm{~mL} / 250 \mathrm{~mL})$ and grown at $37^{\circ} \mathrm{C}$ for $8 \mathrm{~h}$, and the resulting seed was transferred into the second-degree seed medium at $4 \%$ inoculum size and cultivated at $37^{\circ} \mathrm{C}$ for $5-7 \mathrm{~h}$. Finally, the active seed culture was used to inoculate the fermentation medium at a volume ratio of $5 \%$. The fermentation process was carried out at $\mathrm{pH} 7.3$ and $37^{\circ} \mathrm{C}$. The changes of other parameters as well as the production of alkaline protease along with the fermentation in 5 - $\mathrm{L}$ fermenter were investigated. The dissolved oxygen and $\mathrm{pH}$ were self-tested by the fermenter; the biomass was indicated by viable count, and the reducing sugar was assayed by the DNS method.

\section{Statistical analyses}

All experiments were conducted in triplicate, and the experimental data were expressed as the means \pm standard deviations for each sample point. The significance of differences was assessed using two-way ANOVA $(\mathrm{P}<0.05)$. 

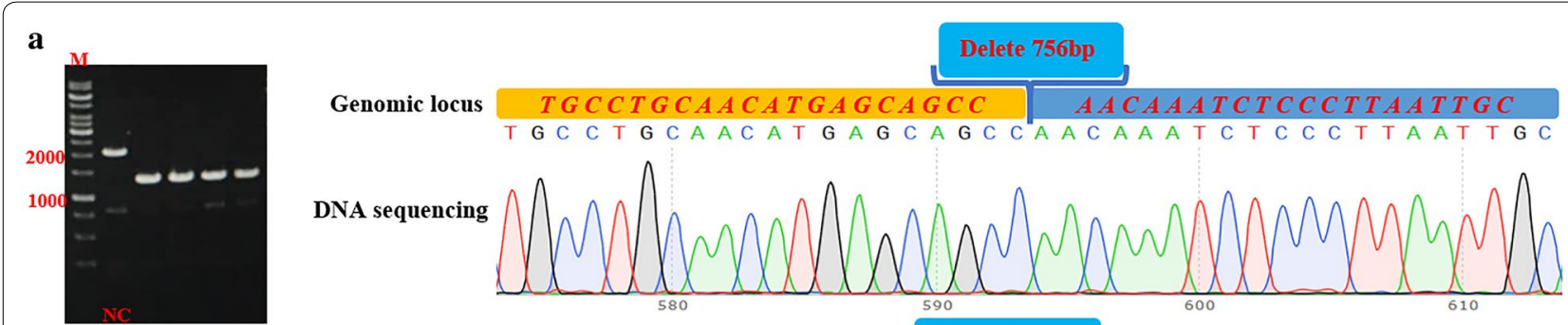

b

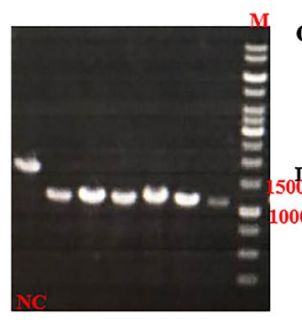

Genomic locus

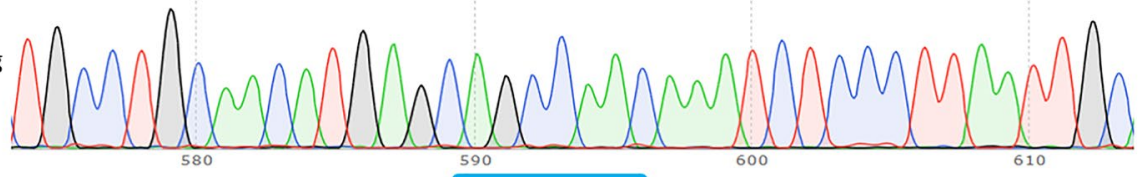

DNA sequencing
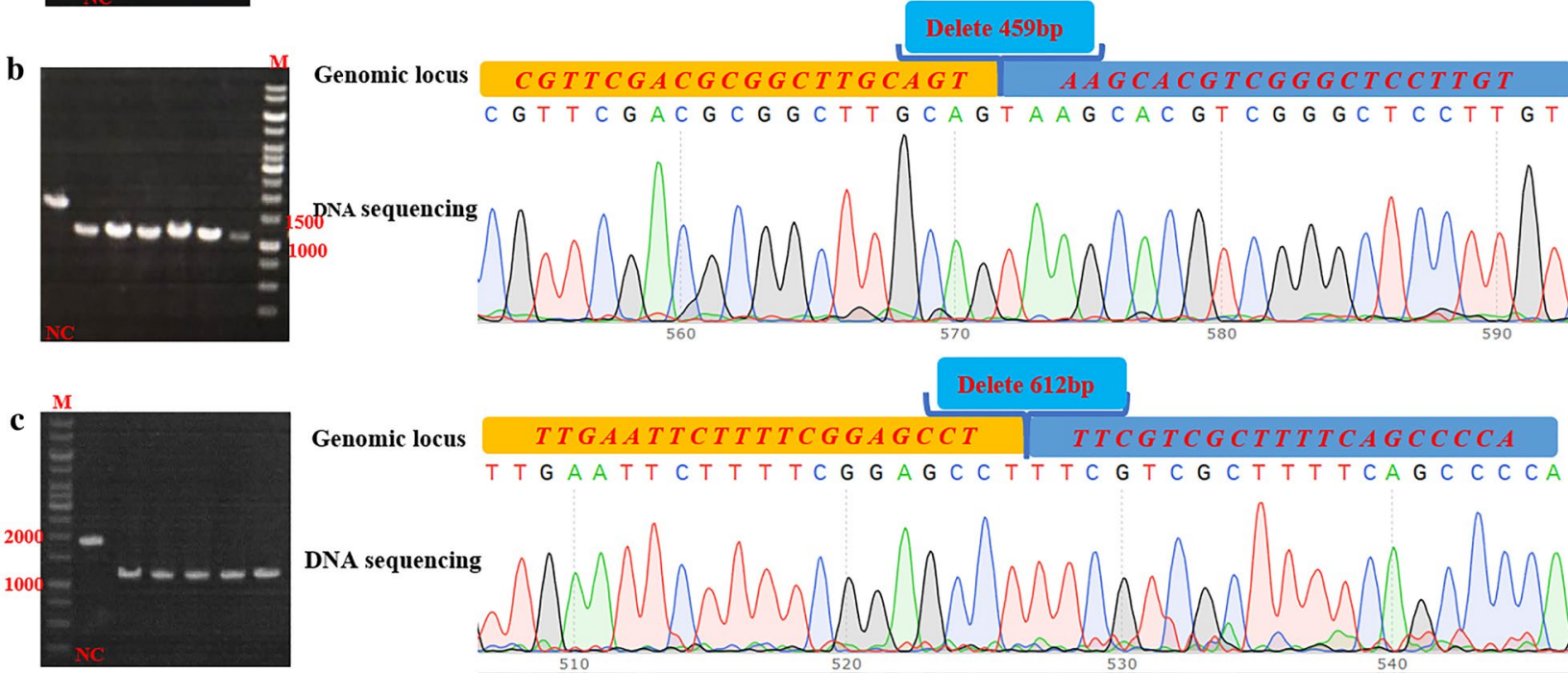

Genomic locus

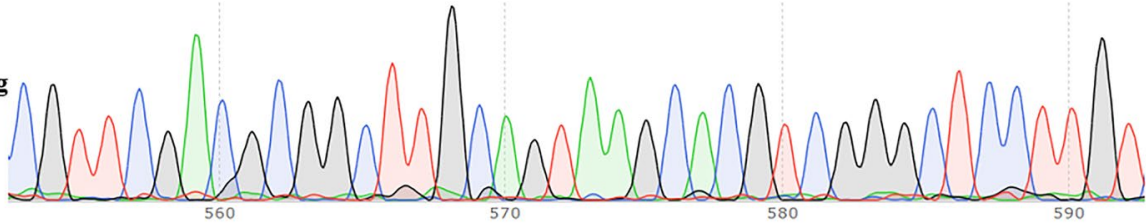
${ }_{50} \mathrm{P}$ Na sequencing (000

\section{(20)}

DNA sequencing

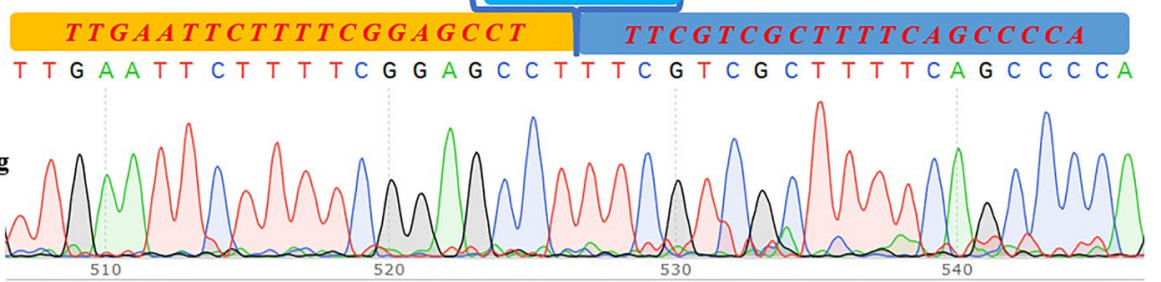

Fig. 2 Confirmation of disruption of spollAC, spoOA and sigE. The DNA sequencing, alignment result of the deletion-carrying mutant and agarose gel electrophoresis; a spollAC deletion, losing 756 bp; b spo0A deletion, losing 459 bp; c sigE gene deletion, losing 612 bp. M: nucleic acid marker; NC: The negative control was obtained by colony PCR of the wild-strain

\section{Results}

\section{Construction of sporulation-deficient strains}

Based on the genome sequence and annotation of B. licheniformis 2709 in our lab, three genes (spo0A, sigE, spoIIAC) encoding spore formation factors were selected. In order to investigated the effect of sporulation on protease synthesis, the spo0A, sigE, spoIIAC genes were deleted in the parent strain $B$. licheniformis $2709 \mathrm{BL}$ $\triangle u p p$, respectively. In the case of the construction of the spo0A knockout plasmid pWHA as an example (Fig. 1), the bands amplified from the mutants had the approximate length of the $\mathrm{HA}$, as well as the sequencing result of the PCR product from the mutant (Fig. 2), confirming that spo0A was disrupted precisely and successfully. The new mutant strain was named $B$. licheniformis $\mathrm{BL}$ $\triangle A$. Similarly, the sigE and spoIIAC genes were deleted using the same method, and the resulting mutants were named $B$. licheniformis BL $\Delta E$ and B. licheniformis BL $\Delta F$, respectively. To prove the observed phenotypes were due to the introduced mutations and to exclude side mutations that may be occasionally produced by CRISPR/Cas9 system, the backcrossed experiment was carried out. The complementary strains were respectively generated by genomic integrating genes of spo0A, sigE, spoIIAC, called BL COA, BL CE and BL CF, which were verified by colony PCR shown in the appendix file (Additional file 1: Fig. $\mathrm{S} 1$ ). The phenotypes (colony form, color, cell growth and enzyme activity) were observed and the results showed no significant difference among the complementary strains and the wild-type strain (data not shown).

\section{Characterization of the mutants}

The deletion strains $\mathrm{BL} \Delta A, \mathrm{BL} \Delta E$ and $\mathrm{BL} \Delta F$ were used for further study. The morphological changes of the three mutations in LB medium at different times were observed using LM and SEM, and the effect of the mutations was clearly visible. When the incubation time was $12 \mathrm{~h}$ there was no difference in cell morphology (rodlike cells) among the mutants and the parent strains (Fig. 3a1, b1). However, when the incubation time was $24 \mathrm{~h}, \mathrm{BL} \Delta E$ and $\mathrm{BL} \Delta F$ had similar cellular morphology with two asymmetric septa in an abortively disporic cell (Fig. 3a3, b2), but the $\mathrm{BL} \Delta A$ still retained rod-shaped cells (Fig. 3a1, b1), and the endospores began to appear in the parent strain (Fig. 3a4) with a sporulation efficiency of $31.3 \%$ (Table 2). All the deletions gave rise to 
a
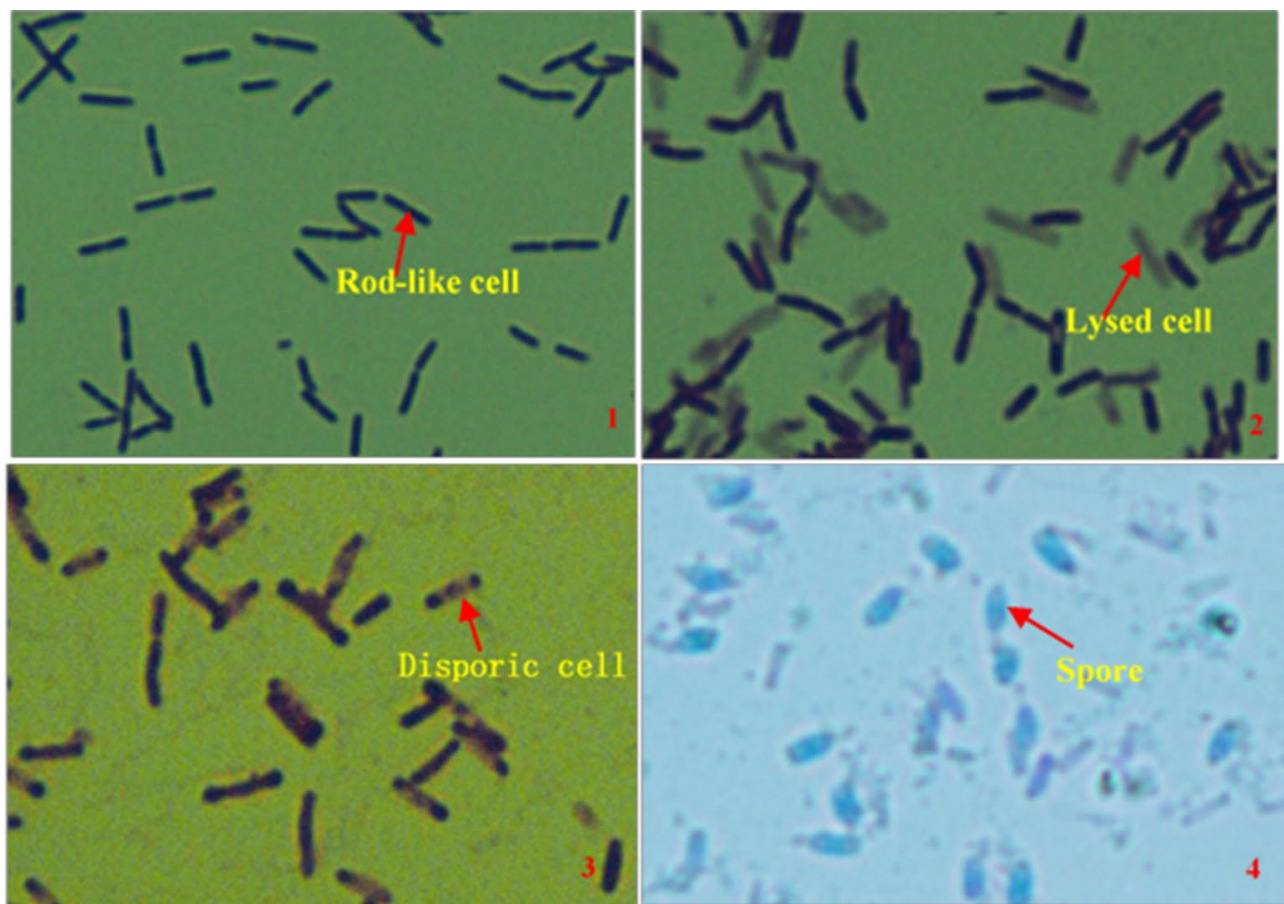

b

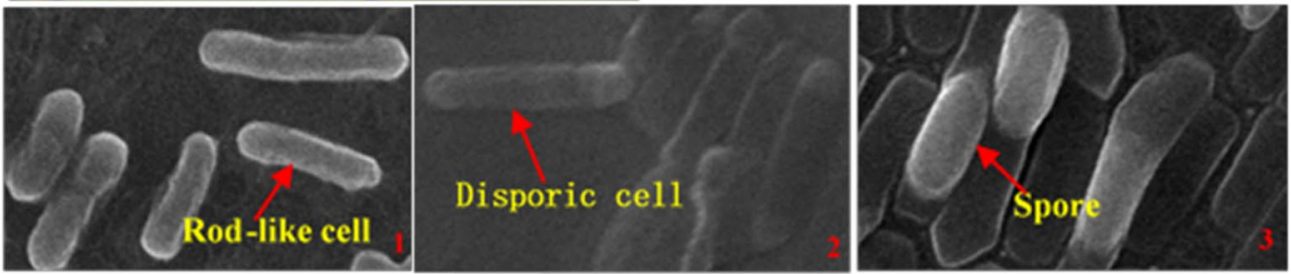

c

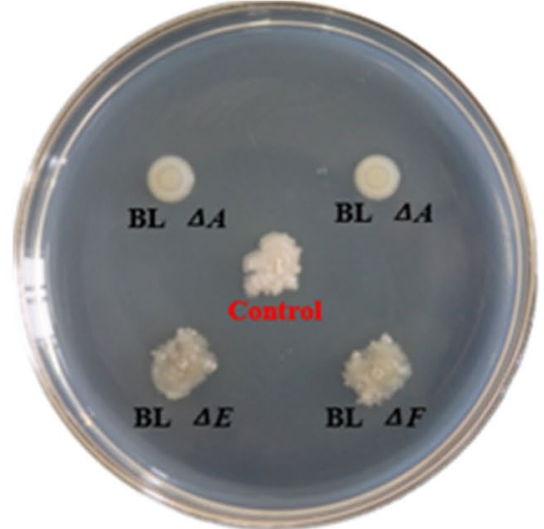

d

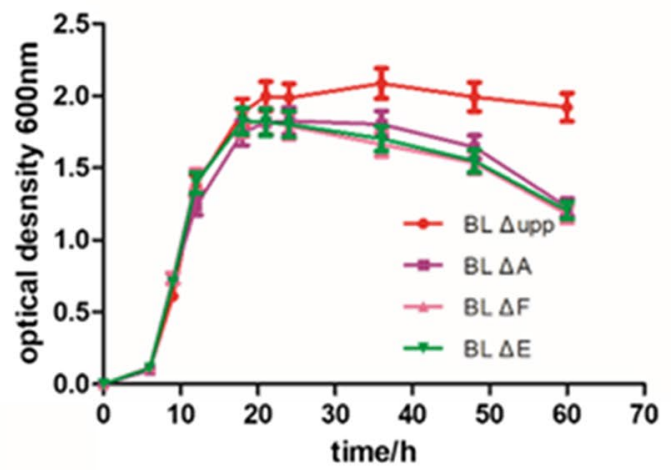

Fig. 3 The characterization of the sporulation-deficient mutants and wild-type strain. The red arrow gave directions of every typical morphology (×100). a The cell morphology was observed by crystal violet (a1-a3) staining assay and Schaeffer-Fulton staining assay (a4): a1, "rod" like cellular morphology of the strains under the optical microscopy $(\mathrm{OM})$; a2, cellular morphology with cell lysis of the spo0A mutant under OM; a3, an abortively disporic cell with two asymmetric septa under $\mathrm{OM}$; $\mathrm{a} 4$, mature endospores in the parent strain under OM. $\mathbf{b}$ The cell morphology was observed under scanning electron microscopy (SEM) (×5000): b1, "rod" like cellular morphology of the strains under SEM; b2, an abortively disporic cell with two asymmetric septa under SEM; b3, mature spores in the parent strain under SEM. c The colonial morphology of the mutants and control strain in LB plate. $\mathbf{d}$ The cell growth curve of different strains

completely asporogenic strains, even after a time period in which the parent strain differentiated into mature spores with a sporulation efficiency of $100 \%$ (Fig. 3a4, b3). Cellular growth was further distinguished by observing cellular morphology under the electron microscope (Fig. 3b), which validated the results obtained by LM. 
Table 2 Viable cell count and sporulation efficiency of different strains in LB medium

\begin{tabular}{|c|c|c|c|c|c|c|c|c|}
\hline \multirow[t]{2}{*}{ Time/h } & \multicolumn{2}{|l|}{ BL $\Delta u p p$} & \multicolumn{2}{|l|}{$\mathrm{BL} \Delta F$} & \multicolumn{2}{|l|}{$\mathrm{BL} \Delta E$} & \multicolumn{2}{|l|}{$\mathrm{BL} \Delta A$} \\
\hline & $\mathrm{cfu} / \mathrm{mL}$ & spo rate/\% & $\mathrm{cfu} / \mathrm{mL}$ & spo rate $/ \%$ & $\mathrm{cfu} / \mathrm{mL}$ & spo rate/\% & $\mathrm{cfu} / \mathrm{mL}$ & spo rate $/ \%$ \\
\hline 12 & $7.9 \times 10^{8}$ & 0 & $7.7 \times 10^{8}$ & 0 & $8.1 \times 10^{8}$ & 0 & $2.4 \times 10^{9}$ & 0 \\
\hline 24 & $2.6 \times 10^{9}$ & 31.3 & $2.5 \times 10^{9}$ & 0 & $2.5 \times 10^{9}$ & 0 & $4.2 \times 10^{9}$ & 0 \\
\hline 36 & $2.7 \times 10^{9}$ & 88.2 & $2.4 \times 10^{9}$ & 0 & $2.5 \times 10^{9}$ & 0 & $2.3 \times 10^{9}$ & 0 \\
\hline 48 & $1.6 \times 10^{9}$ & 97.8 & $9.3 \times 10^{6}$ & 0 & $1.1 \times 10^{7}$ & 0 & $1.5 \times 10^{7}$ & 0 \\
\hline 60 & $1.4 \times 10^{9}$ & 100.0 & $8.5 \times 10^{5}$ & 0 & $8.7 \times 10^{5}$ & 0 & $8.1 \times 10^{5}$ & 0 \\
\hline
\end{tabular}
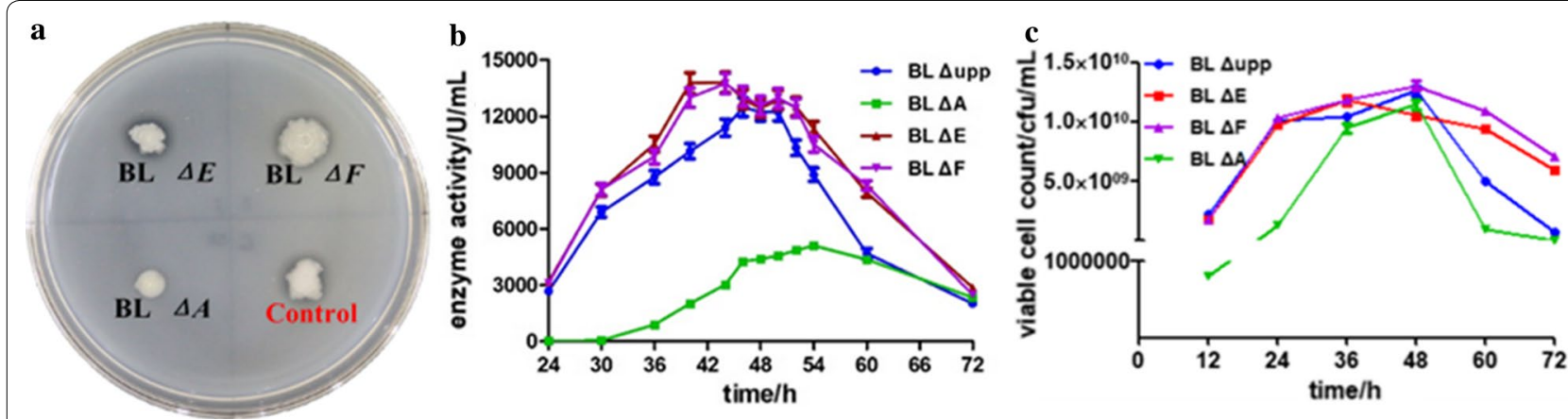

Fig. 4 Alkaline protease synthesis measured in different strains. a Detection of protease in Buttermilk plate; $\mathbf{b}$ alkaline protease enzyme activity assay of the mutants and wild-type strain; $\mathbf{c}$ the viable cell count of the mutants and wild-type strain

Furthermore, the morphology of the strains' colonies on LB plates was compared and there were obvious differences in form or color. The colony form of BL $\Delta E$ and $\mathrm{BL}$ $\Delta F$ was random, which was similar to that of the parent strain except for the colony color. By contrast, the colonies of BL $\Delta A$ were tidy and round (Fig. 3c).

After growth in LB medium for $60 \mathrm{~h}$, the viability of the strains was reflected in the cell growth curves (Fig. 3d), and the number of viable bacteria and sporulation frequency were quantified (Table 2). There were some differences between the parent strain and the mutants, whereby the $\mathrm{OD}_{600}$ of the control was stabilized at about 2.0 , while that of the sigE and sigF mutants gradually decreased as shown in Fig. 3d, which may be attributed to the insufficiently rich medium and not to cell lysis as shown in Fig. 3a3. When the two strains cultured in BHI medium, the cell population remained steady at about $2.5 \times 10^{9} \mathrm{cfu} / \mathrm{mL}$ (data not shown) throughout the incubation period of $72 \mathrm{~h}$, which was in accordance with the data for same strains cultured in LB medium for $36 \mathrm{~h}$ (Table 2). However, although the spo0A mutant did not present any obvious defects in cell growth from the exponential to the early stationary phase (Fig. 3d), its cell density and viable cell count markedly decreased after $24 \mathrm{~h}$ (Table 2). Together with the changes cellular morphology observed under the optical microscope (Fig. 3a2) we concluded that autolysis likely occurred in the spo0A mutant.
Therefore, it can be said that despite the changes of sporogenicity, there was no indication of loss of viability or cell lysis in the $s i g \mathrm{E}$ and sigF mutants when grown in LB medium and the spo0A mutant was prone to cell lysis.

\section{Production of alkaline protease by the different spore-formation mutants}

The results of the initial buttermilk plate tests suggested that the sigE and sigF mutant strains differed slightly from the control strain in the amounts of extracellular protease they produced. However, the spo0A deletion resulted in a loss of the ability to synthesize protease as evidenced by the smaller hydrolysis zones, which indicated that the synthesis of protease was seriously affected by the DNA binding protein Spo0A (Fig. 4a). We next monitored the synthesis of alkaline protease when the strains were grown in fermentation medium for $72 \mathrm{~h}$ (Fig. 4b). The protease yield was higher in the sigE and sigF mutants than in the parent strain, particularly later in the growth cycle, whereby the enzyme activity of the two mutants decreased more slowly. The enzyme yield peaked after incubation for about $40 \mathrm{~h}$ in both mutants and then remained steady for about $12 \mathrm{~h}$, while the parent strain reached its maximum enzyme activity at $46 \mathrm{~h}$, and the stationary phase lasted only about $6 \mathrm{~h}$. By contrast, the synthesis of protease greatly repressed in the 


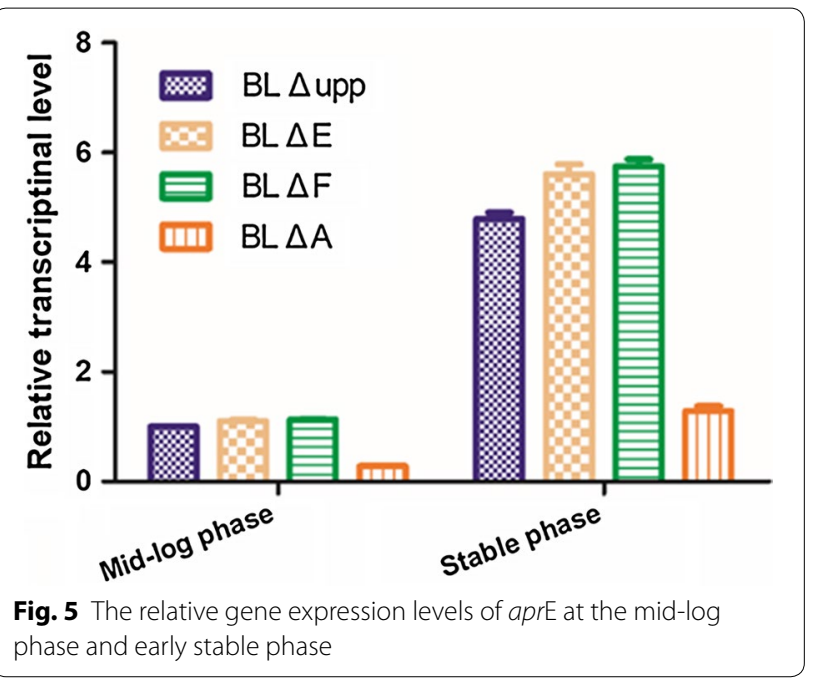

spo0A mutant, which reached the highest enzyme activity of only $5100 \mathrm{U} / \mathrm{mL}$ after incubation for $54 \mathrm{~h}$.

However, considering the possible effect of biomass on the synthesis and accumulation of the enzyme, a viable count was performed at different culture times to assess alkaline protease activity per unit biomass (Fig. 4c). We found that, the cell growth was seriously influenced by the Spo0A in the fermentation medium, but there was no significant difference between the other two mutants and the wild-type strain except that the viable cell count of the two mutants was higher than that of the control strain in the later growth stage. Thus, the $s i g \mathrm{E}$ and $s i g \mathrm{~F}$ mutants also performed somewhat better than the parent, but the deletion of spo0A resulted in a loss of the ability to synthesize extracellular protease. All the mutants remained asporous throughout the whole fermentation process and the morphological changes were similar to those observed when the strains were cultured in LB medium. These results indicated that the sporulation-deficiency of sigE and sigF had no negative effect on protease synthesis, and that $\mathrm{BL} \Delta E$ and $\mathrm{BL} \Delta F$ may be excellent alternative strains for industrial enzyme production.

\section{Transcriptional analysis of the alkaline protease gene in the mutant strains}

In view of the dramatic difference between the spo0A mutant and the other three strains in alkaline protease activity when cultivated in fermentation medium, the relative gene expression levels of the aprE gene were evaluated at the mid-log phase $(26 \mathrm{~h})$ and the early stable phase $(40 \mathrm{~h})$ in the parental strain, BL $\Delta E$ and BL $\Delta F$ during the protease production process, as well as at $40 \mathrm{~h}$ and $48 \mathrm{~h}$, respectively in $\mathrm{BL} \Delta A$. As shown in Fig. 5 , the aprE transcriptional level in $\mathrm{BL} \Delta E$ and $\mathrm{BL} \Delta F$ were increased by about $25 \%$ compared to the control strain at both stages, while in the BL $\Delta A$ it was dramatically affected, reaching only about 0.3 -fold of the control value. Importantly, in the early stable phase the $a p r E$ transcriptional levels of all the strains were increased about fourfold compared with the mid-log phase, indicating that aprE expression was initiated in the late phase of cell growth.

\section{Enhanced protease production in a 5-L fermenter}

Fed-batch fermentation was applied to improve the yield of alkaline protease using BL $\Delta F$ and the control strain based on the studies of metabolic processes during batch fermentation in a 5 - $\mathrm{L}$ auto-fermenter. The concentration of biomass (as a proxy for the viable bacteria count) and reducing sugars were determined in real time to control the $\mathrm{pH}$, dissolved oxygen and to optimize the fed-batch fermentation strategy by making fine adjustments. The changes of different parameters during the fermentation were shown in Table 3. The $\mathrm{pH}$, concentration of reducing sugars and dissolved oxygen was as far as possible kept at about $7.3,15 \%$ and $35 \%$, respectively, meanwhile the highest relative activity of alkaline protease was obtained. As shown in Fig. 6, the production of alkaline protease remained at a relatively higher level of $19.7 \%$ in $\mathrm{BL} \Delta F$ compared with that obtained in the control strain

Table 3 Changes of different parameters during fermentation in $5 \mathrm{~L}$ fermenter of BL $\Delta$ upp and BL $\Delta F$

\begin{tabular}{|c|c|c|c|c|c|c|c|c|}
\hline \multirow[t]{2}{*}{ Time/h } & \multicolumn{4}{|l|}{ BL $\Delta u p p$} & \multicolumn{4}{|l|}{$\mathrm{BL} \Delta F$} \\
\hline & $\mathrm{VC} / \mathrm{cfu} / \mathrm{mL}$ & $\mathrm{DO}_{2} / \%$ & $\mathrm{pH}$ & $\mathrm{RS} / \%$ & $\mathrm{VC} / \mathrm{cfu} / \mathrm{mL}$ & $\mathrm{DO}_{2} / \%$ & $\mathrm{pH}$ & $\mathrm{RS} / \%$ \\
\hline 0 & $5.71 \times 10^{4}$ & 90 & 7.28 & 23.67 & $6.33 \times 10^{4}$ & 90 & 7.26 & 24.18 \\
\hline 12 & $4.95 \times 10^{8}$ & 53.4 & 7.13 & 19.70 & $5.86 \times 10^{8}$ & 50.7 & 7.16 & 20.03 \\
\hline 24 & $1.23 \times 10^{10}$ & 32.0 & 6.97 & 16.76 & $1.44 \times 10^{10}$ & 33.6 & 7.23 & 16.85 \\
\hline 36 & $1.87 \times 10^{10}$ & 37.9 & 7.11 & 16.64 & $2.09 \times 10^{10}$ & 34.9 & 7.19 & 16.54 \\
\hline 48 & $3.62 \times 10^{10}$ & 35.7 & 7.10 & 15.89 & $3.13 \times 10^{10}$ & 36.3 & 7.15 & 16.16 \\
\hline 60 & $3.47 \times 10^{10}$ & 36.1 & 7.17 & 16.12 & $2.95 \times 10^{10}$ & 35.5 & 7.19 & 17.04 \\
\hline 72 & $1.96 \times 10^{10}$ & 37.4 & 7.09 & 16.06 & $2.46 \times 10^{10}$ & 36.2 & 7.11 & 16.51 \\
\hline
\end{tabular}

$V C$ viable counts, $D_{2}$ dissolved oxygen, $R S$ represents reducing sugar 


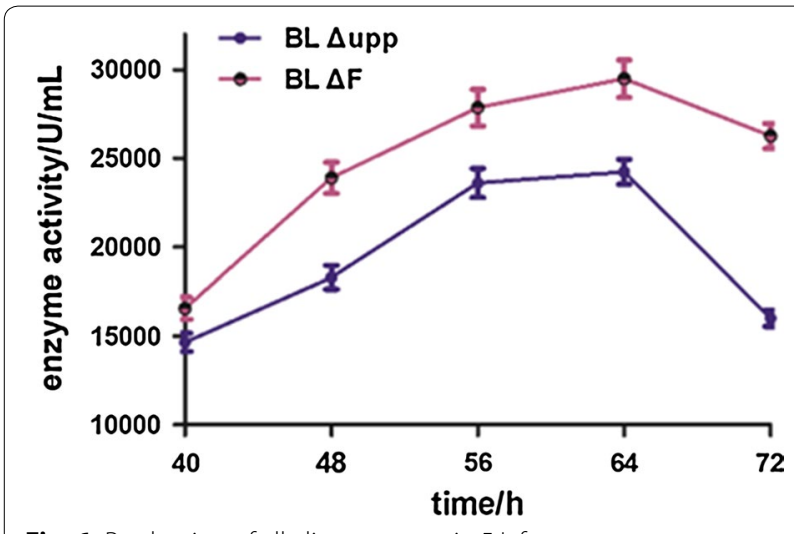

Fig. 6 Production of alkaline protease in $5 \mathrm{~L}$ fermenter

BL $\Delta u p p$. Also, when the incubation time was $48 \mathrm{~h}$, the enzyme activity of BL $\Delta F$ reached to $23,910 \pm 885 \mathrm{U} / \mathrm{mL}$, and up to $29,494 \pm 1053 \mathrm{U} / \mathrm{mL}$ at $64 \mathrm{~h}$, showing that the stable period was longer by about $16 \mathrm{~h}$ in the 5 - $\mathrm{L}$ fermenter. It is worth mentioning that the enzyme yield of BL $\Delta F$ declined more slowly, and the result resembled that obtained in the shake flasks, which might be due to the change trend of biomass (Table 3).

\section{Discussion}

Gene excision and integration is a frequently-used procedure for engineering specific mutations in Bacillus and other Gram-positive bacteria [33-35]. Over the past several years, the CRISPR-Cas-based adaptive immune system from bacteria and archaea has been repurposed for versatile genome editing or transcriptional regulation in many different species. In particular, methods based on the Type II CRISPR/Cas9 system have been widely used in Bacillus [21, 36], and have also been harnessed for genome editing to construct targeted mutants in $B$. licheniformis by our own group [7]. In this work, we further demonstrated that the procedure could be applied to achieve efficient chromosome editing to successfully construct three sporulation-deficient strains.

Bacillus licheniformis has the generally recognized as safe (GRAS) status, which has promoted its development as a host strain in the pharmaceutical and nutraceutical industries [37]. However, endospore formation is a harmful undomesticated characteristic that is activated in response to an adverse growth environment and can strongly impact the production safety [14]. Several general strategies for the successful development of industrial hosts were introduced to obtain Bacillus cellular factories with improved cellular performances [38]. Given this, we realized that deleting sporulation-related genes might lead to an improvement of enzyme productivity. Our understanding of the genetics of sporulation in B. licheniformis is now at an advanced stage, and with the aid of the complete genome sequence, spore-related genes have been well characterized. To initiate sporulation, the master regulator of sporulation Spo0A activates the expression of the sporulation-specific RNA polymerase $\sigma$ factor, SigF, in the forespore. This sigma factor is the product of the spoIIAC gene and the first sigma factor in the regulatory cascade that controls sporulation [39]. SigF in turn activates SigE protein, the first mothercell-specific sigma factor [26]. Thus, in this case, we constructed $s p o 0 \mathrm{~A}, s i g \mathrm{E}$ and $s i g \mathrm{~F}$ mutants to investigate the effects of sporulation on protease production.

As the results shown in Fig. 3a3 indicate, normal asymmetric septum formation was inhibited in both sigEdeleted and sigF-defective mutants, which displayed 'bipolar' or 'disporic' cells with the septum formed at both ends, which resulted in mature endospore formation being blocked as reported previously [20, 40]. Because they are sporulation-specific factors that are active during sporulation stage II, depletion of the two sigma factors had no effect on cell growth and bacteriolysis. However, deletion of the DNA-binding protein Spo0A had obvious detrimental effects on cell growth, such as changes cellular and colony morphology, increased cell lysis, and reduction of the enzyme yield, which can be explained by the "transition state" (such as motility, protease production, competence and biofilm formation) resulting from the initial activation of Spo0A [18]. Some researchers found that mutations affecting stage II of sporulation have little effect on the production of extracellular enzymes because they are generally synthesized in the late exponential phase and the early stationary phase [41]. In fact, such changes could even improve cellulase productivity [22], whereas protease activity was significantly decreased in the spo0A mutant [23]. Fortunately, when we investigated the effect of sporulation on alkaline protease synthesis, a yield-enhanced sporulation-deficient $B$. licheniformis called BL $\Delta F$ was successfully established, whose aprE gene transcriptional level was apparently improved. Importantly, the BL $\Delta F$ was superior in operation simpleness, energy conservation, and target product controlling effect due to the tremendously prolonged stable phase of enzyme production; furthermore, the enzyme yield declined more slowly compared with the control strain, which has great value for industrial applications [15]. The advanced performance could help avoid large losses of the target enzyme during industrial production [42]. The BL $\Delta F$ strain was completely asporogenic, absolutely stable and unable to revert to sporogeny, while also outperforming the parent strain in the synthesis and secretion of extracellular enzymes.

Traits favorable for the synthesis of extracellular enzymes are induced during the transition from 
exponential growth to the stationary phase in batch culture, suggesting that sporulation and protease production might be coregulated [43]. However, whether the metabolic activities of the cell led to the improvement of protease activity remains unclear. Furthermore, the link between Spo0A and the production of extracellular enzymes in B. licheniformis was not systematically investigated. We will next study the genes related to the transcription, translation and secretion apparatuses, as well as cell cycle-related, ATP-synthesis-related, transporter-related and stress response-related genes via RNA sequencing, genome and transcriptome analyses of the mutants and control strain. Although its capacity to produce alkaline protease was severely reduced, the spo0A mutant might be a better host for the production of extracellular proteins, because its function resembles the multiple-protease-deficient mutants with very low protease activity. If the role of SpoOA in alkaline protease synthesis can be confirmed in future studies, the mutants can be employed directly to produce other target proteins with higher efficiency. Thus, we will further investigate the regulatory mechanisms of Spo0A protein in B. licheniformis in the future.

\section{Conclusions}

The major aim of this work was to investigate the effect of sporulation on protease production and engineered an industrial host with excellent performance. We constructed three asporogenous strains of $B$. licheniformis using a previously established CRISPR/Cas9 system. All the mutants were asporogenic as predicted, and the mutations affecting stage II of sporulation increased the production of alkaline protease efficiently. Therefore, we concluded that introducing a deletion in the $\operatorname{sig} \mathrm{E}$ or spoIIAC gene can produce a mutant that retains the important industrial properties and preferable characteristics, while prolonging the stable phase of enzyme activity and leading to a slower decline, which has great application value in industrial production. In summary, this work provides an industrial strain with excellent performance and a novel strategy to enhance protease synthesis.

\section{Additional file}

Additional file 1: Table S1. Main oligonucleotides used in this study. Table S2. Main oligonucleotides used in backcrossed experiment. Fig. S1. Confirmation of complementation of sigF, spoOA and sigE. Agarose gel electrophoresis: spollAC, insertion 756bp; spo0A, insertion 459bp; sigE insertion $612 \mathrm{bp}$. M: nucleic acid marker; NC: The negative control was obtained by colony PCR of the specific sporulation-deficient mutant.
Acknowledgements

We are grateful to professor Cunjiang Song (NanKai University) and professor Tingyi Wen (Chinese Academy of Sciences) for kindly providing the plasmid pWH1520, as well as the strains E. coli EC135 and EC135 pM.Bam.

\section{Authors' contributions}

$\mathrm{CZ}$ and $\mathrm{HZ}$ designed this study. CZ and $\mathrm{HZ}$ performed most experiments. All the authors analyzed the data. $\mathrm{CZ}$ and $\mathrm{HZ}$ mainly wrote the manuscript. All authors read and approved the final manuscript.

\section{Funding}

This work was supported by the National Key Research and Development Program of China (2017YFB0308401), and in part by the National Natural Science Foundation of China (81373309) and Tianjin Natural Science Foundation (18JCYBJC43400).

\section{Availability of data and materials}

All data generated or analyzed during this study are included in this published article.

Ethics approval and consent to participate Not applicable.

\section{Consent for publication}

Not applicable.

\section{Competing interests}

The authors declare that they have no competing interests.

Received: 25 April 2019 Accepted: 17 July 2019

Published online: 25 July 2019

References

1. Ibrahim AS, Al-Salamah AA, El-Badawi YB, El-Tayeb MA, Antranikian G. Detergent-, solvent- and salt-compatible thermoactive alkaline serine protease from halotolerant alkaliphilic Bacillus sp. NPST-AK15: purification and characterization. Extremophiles. 2015;19:961-71.

2. Yildirim V, Baltaci MO, Ozgencli I, Sisecioglu M, Adiguzel A, Adiguzel G. Purification and biochemical characterization of a novel thermostable serine alkaline protease from Aeribacillus pallidus C10: a potential additive for detergents. J Enzyme Inhib Med Chem. 2017;32:468-77.

3. Abdel-Naby MA, Ahmed SA, Wehaidy HR, El-Mahdy SA. Catalytic, kinetic and thermodynamic properties of stabilized Bacillus stearothermophilus alkaline protease. Int J Biol Macromol. 2017:96:265-71.

4. Hammami A, Hamdi M, Abdelhedi O, Jridi M, Nasri M, Bayoudh A. Surfactant- and oxidant-stable alkaline proteases from Bacillus invictae: characterization and potential applications in chitin extraction and as a detergent additive. Int J Biol Macromol. 2017;96:272-81.

5. Schallmey M, Singh A, Ward OP. Developments in the use of Bacillus species for industrial production. Can J Microbiol. 2004;50:1-17.

6. Wiegand S, Voigt B, Albrecht D, Bongaerts J, Evers S, Hecker M, Daniel $\mathrm{R}$, Liesegang $\mathrm{H}$. Fermentation stage-dependent adaptations of Bacillus licheniformis during enzyme production. Microb Cell Fact. 2013;12:120.

7. Zhou C, Liu H, Yuan F, Chai H, Wang H, Liu F, Li Y, Zhang H, Lu F. Development and application of a CRISPR/Cas9 system for Bacillus licheniformis genome editing. Int J Biol Macromol. 2019;122:329-37.

8. Wei X, Zhou Y, Chen J, Cai D, Wang D, Qi G, Chen S. Efficient expression of nattokinase in Bacillus licheniformis: host strain construction and signal peptide optimization. J Ind Microbiol Biotechnol. 2015;42:287-95.

9. Harwood CR, Mouillon JM, Pohl S, Arnau J. Secondary metabolite production and the safety of industrially important members of the Bacillus subtilis group. FEMS Microbiol Rev. 2018:42:721-38.

10. Voigt B, Schroeter R, Schweder T, Jurgen B, Albrecht D, van Dijl JM, Maurer $\mathrm{KH}$, Hecker M. A proteomic view of cell physiology of the industrial workhorse Bacillus licheniformis. J Biotechnol. 2014;191:139-49.

11. Grimbergen AJ, Siebring J, Solopova A, Kuipers OP. Microbial bet-hedging: the power of being different. Curr Opin Microbiol. 2015;25:67-72. 
12. Hecker M, Volker U. Towards a comprehensive understanding of Bacillus subtilis cell physiology by physiological proteomics. Proteomics. 2004:4:3727-50.

13. Dijl J, Hecker M. Bacillus subtilis: from soil bacterium to supersecreting cell factory. Microb Cell Fact. 2013;12:3.

14. Bressuire-Isoard C, Broussolle V, Carlin F. Sporulation environment influences spore properties in Bacillus: evidence and insights on underlying molecular and physiological mechanisms. FEMS Microbiol Rev. 2018:42:614-26.

15. LiT, Chen XB, Chen JC, Wu Q, Chen GQ. Open and continuous fermentation: products, conditions and bioprocess economy. Biotechnol J. 2014;9:1503-11.

16. Tocheva El, Ortega DR, Jensen GJ. Sporulation, bacterial cell envelopes and the origin of life. Nat Rev Microbiol. 2016;14:535-42.

17. Keynan A, Sandier N. Spore research in historical perspective. The bacterial spore, vol. 2. London: Academic Press Ltd; 1984. p. 1-48.

18. Hilbert DW, Piggot PJ. Compartmentalization of gene expression during Bacillus subtilis spore formation. Microbiol Mol Biol Rev. 2004;68:234-62.

19. Zhang J, Zong W, Hong W, Zhang ZT, Wang Y. Exploiting endogenous CRISPR-Cas system for multiplex genome editing in Clostridium tyrobutyricum and engineer the strain for high-level butanol production. Metab Eng. 2018;47:49-59.

20. Mascher G, Mertaoja A, Korkeala H, Lindstrom M. Neurotoxin synthesis is positively regulated by the sporulation transcription factor Spo0A in Clostridium botulinum type E. Environ Microbiol. 2017;19:4287-300.

21. Zhang K, Duan X, Wu J. Multigene disruption in undomesticated Bacillus subtilis ATCC 6051a using the CRISPR/Cas9 system. Sci Rep. 2016;6:27943.

22. Ara K, Ozaki K, Nakamura K, Yamane K, Sekiguchi J, Ogasawara N. Bacillus minimum genome factory: effective utilization of microbial genome information. Biotechnol Appl Biochem. 2007;46:169-78.

23. Eugenio F, Sandra M, James A. Effect of stage 0 sporulation mutations on subtilisin expression. J Bacteriol. 1986;166:173-9.

24. Kodama T, Endo K, Ara K, Ozaki K, Kakeshita H, Yamane K, Sekiguchi J. Effect of Bacillus subtilis spo0A mutation on cell wall lytic enzymes and extracellular proteases, and prevention of cell lysis. J Biosci Bioeng. 2007;103:13-21.

25. Abraham L. Control of sporulation initiation in Bacillus subtilis. Curr Opin Microbiol. 2000;3:561-6.

26. Piggot PJ, Hilbert DW. Sporulation of Bacillus subtilis. Curr Opin Microbiol. 2004;7:579-86.

27. Lapidus A, Galleron N, Andersen J, Ehrlich S, Sorokin A. Co-linear scajold of the Bacillus licheniformis and Bacillus subtilis genomes and its use to compare their competence genes. FEMS Microbiol Lett. 2002;209:23-30.

28. Fleming AB, Tangney M, Jorgensen PL, Diderichsen B, Priest FG. Extracellular enzyme synthesis in a sporulation-deficient strain of Bacillus licheniformis. Appl Environ Microbiol. 1995:61:3775-80.

29. Zhang G, Wang W, Deng A, Sun Z, Zhang Y, Liang Y, Che Y, Wen T. A mimicking-of-DNA-methylation-patterns pipeline for overcoming the restriction barrier of bacteria. PLoS Genet. 2012;8:e1002987.
30. Ong KS, Aw YK, Lee LH, Yule CM, Cheow YL, Lee SM. Burkholderia paludis sp. nov., an antibiotic-siderophore producing novel Burkholderia cepacia complex species, isolated from Malaysian Tropical peat swamp soil. Front Microbiol. 2016;7:2046.

31. National food safety standard of the People's Republic of China: The National Standardization Administration Commission GB/T 4789.35-2010, Food microbiological examination: Lactic acid bacteria. 2010.

32. State Administration for Quality Supervision and Inspection and Quarantine of the People's Republic of China: The National Standardization Administration Commission GB/T 23527-2009, Proteinase preparations. 2009.

33. Indranil B, Alexandra G, Ehrlich S, Emmanuelle M. High-efficiency gene inactivation and replacement system for gram-positive bacteria. J Bacteriol. 1993;175:3628-35.

34. Martin T, Per L, Berge D, Steen T. A new method for integration and stable DNA amplification in poorly transformable bacilli. FEMS Microbiol Lett. 1995;125:107-14.

35. Ireton K, Rudner DZ, Siranosian KJ, Grossman AD. Integration of multiple developmental signals in Bacillus subtilis through the SpoOA transcription factor. Genes Dev. 1993;7:283-94.

36. Li K, Cai D, Wang Z, He Z, Chen S. Development of an efficient genome editing tool in Bacillus licheniformis using CRISPR-Cas9 Nickase. Appl Environ Microbiol. 2018. https://doi.org/10.1128/AEM.02608-17

37. Jin P, Zhang L, Yuan P, Kang Z, Du G, Chen J. Efficient biosynthesis of polysaccharides chondroitin and heparosan by metabolically engineered Bacillus subtilis. Carbohydr Polym. 2016;140:424-32.

38. Dong H, Zhang D. Current development in genetic engineering strategies of Bacillus species. Microb Cell Fact. 2014;13:63.

39. Wu J, Howard M, Piggot P. Regulation of transcription of the Bacillus subtilis spollA locus. J Bacteriol. 1989;171:692-8.

40. Al-Hinai MA, Jones SW, Papoutsakis ET. The Clostridium sporulation programs: diversity and preservation of endospore differentiation. Microbiol Mol Biol Rev. 2015;79:19-37.

41. Priest FG. Extracellular enzyme synthesis in the genus Bacillus. Bacteriol Rev. 1977;41:711-53.

42. Gupta R, Beg QK, Lorenz P. Bacterial alkaline proteases: molecular approaches and industrial applications. Appl Microbiol Biotechnol. 2002:59:15-32.

43. Kirk DG, Zhang Z, Korkeala H, Lindstrom M. Alternative sigma factors SigF, SigE, and SigG are essential for sporulation in Clostridium botulinum ATCC 3502. Appl Environ Microbiol. 2014;80:5141-50.

\section{Publisher's Note}

Springer Nature remains neutral with regard to jurisdictional claims in published maps and institutional affiliations.

\footnotetext{
Ready to submit your research? Choose BMC and benefit from:

- fast, convenient online submission

- thorough peer review by experienced researchers in your field

- rapid publication on acceptance

- support for research data, including large and complex data types

- gold Open Access which fosters wider collaboration and increased citations

- maximum visibility for your research: over $100 \mathrm{M}$ website views per year
}

At BMC, research is always in progress.

Learn more biomedcentral.com/submissions 